Teknokultura. Revista de Cultura Digital y Movimientos Sociales

ISSNe: 1549-2230

\title{
Reseña/Review (Prádanos, Luis I., "Postgrowth Imaginaries. New ecologies and counterhegemonic culture in post-2008 Spain", Liverpool, Liverpool University Press, ISBN: 978-1-78694-134-3, 246 págs., 2018) ${ }^{1}$
}

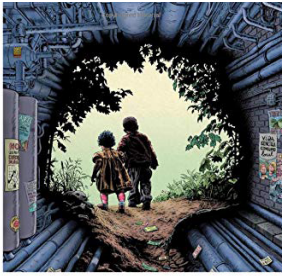

Este libro de Iñaki Prádanos es un aporte mayor al todavía incipiente campo de las humanidades ambientales -aunque parece imponerse el término de humanidades ambientales, una traducción directa de las Environmental $\mathrm{Hu}$ manaties del mundo anglosajón, postgrowth imaginaries culture in post-2008 spai
botic

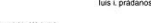
quizá convendría que más bien hablásemos de humanidades ecológicas para captar la diferencia que separa al ambientalismo del ecologismo-. Aunque se publique en inglés, en una editorial universitaria y con un precio no muy asequible, es indudable que el texto palpita con los debates políticos, las preocupaciones sociales y las creaciones culturales e institucionales de la España del periodo post-2008. El libro ofrece a la vez un marco teórico sistemático y un ilustrativo recorrido a través de las creaciones culturales que han tratado de reflexionar en torno a problemáticas socio-ecológicas utilizando las herramientas propias de las humanidades.

En la primera parte del texto, "Cultura española y economía poscrecimiento", el autor presenta un marco teórico que combina los estudios culturales con la economía poscrecimiento para crear lo que denomina un "eco-criticismo ibérico". El objetivo de este ecocriticismo es constituir una herramienta que permita estudiar tanto las contradicciones del paradigma cultural dominante, fundamentalmente caracterizado por su obsesión con el crecimiento y por su marco antropológico neoliberal (Laval y Dardot, 2013), como los obstáculos que éste plantea a la hora de hacer frente a nuestro presente entendido como el de la crisis global del Antropoceno (Steffen et al., 2015).

En el desarrollo de esta parte es de celebrar el modo en que Prádanos ofrece una visión sintética de las implicaciones ecológicas del Antropoceno. Además, a esta descripción se le une una crítica del crecimiento económico que tiene la sensibilidad e inteligencia de no incurrir en la fantasía de que bastaría con volver a antes de 2008 para que todos nuestros problemas se solucionaran (Prádanos, 2018). El autor tiene claro que sin una transformación social radical que nos aleje de las dinámicas expansivas del capitalismo no es posible hacer frente a la destrucción socio-ecológica en curso.

Quizá uno de los puntos flacos de todo el trabajo de Prádanos sea el hecho de que, a la hora de diagnosticar nuestro presente, asuma de manera bastante acrítica la herencia de los estudios culturales nacidos de la recepción estadounidense del postestructuralismo francés conocida como french theory (Cusset, 2005). Algunos ejemplos pueden ilustrar cómo los fines del autor, por otro lado, compartidos con quien escribe, se ven más empañados que esclarecidos por esta asunción.

Prádanos otorga también un papel central a los imaginarios (2018), algo fundamental para plantar cara a la obsesión por el crecimiento que lleva al menos cinco décadas atenazando a nuestras sociedades. Pero, pese a una referencia inicial a Castoriadis $(1983,1989)$ como introductor de este término y responsable de señalar su importancia para pensar nuestras sociedades y transformarlas, el marco que elije en el desarrollo del libro para pensar los imaginarios es más bien el de Agamben.

Para Prádanos el responsable de nuestra imposibilidad para imaginar sociedades poscarbono, poscrecimiento, poscapitalistas, posneoliberales, pospatriarcales y decoloniales (Prádanos, 2018) es el dispositivo (Agamben, 2011) que Agamben define como "máquina antropológica":

The roots of the pervasive neoliberal mindset are nourished by previously drawn hierarchical distinctions $[. .$.$] or what Giorgio Agamben calls the 'an-$ thropological machine' [ ]. Humanity is defined and redefined again and again in opposition to the animal other, and it is the self-proclaimed 'proper humans' [...]. That which does not fit into the 'properly human' category constructed by the 'anthropological machine' at a given historical moment is deemed inferior and may be exploited without ethical concern or legal consequence (Prádanos, 2018, p. 25).

Pero, ¿qué procedimiento sigue la humanidad para realizar esa definición? ¿Cómo se construye una episteme, en el lenguaje de Foucault? El modo en que estos teóricos han reducido el lazo social a una colección de lazos lingüísticos, hegemonías, agonismos o movimien-

Esta reseña ha sido realizada en el marco de los siguientes proyectos de investigación: Proyecto BICOM «Bienes comunes: conceptualización y articulación cívica y jurídica», cuya referencia es SI/PJI/2019-00474; «Racionalidad económica, ecología política y globalización: hacia una nueva racionalidad cosmopolita», cuya referencia es PID2019-109252RB-Ioo; y «Humanidades ecológicas y transiciones ecosociales. Propuestas éticas, estéticas y pedagógicas para el Antropoceno», cuya referencia es PID2019-107757RB-Ioo. 
tos retóricos siguiendo al Lyotard de la La condición posmoderna (1989), lleva en muchas ocasiones a reducir la construcción de estos imaginarios a una dimensión puramente cultural, o a lo sumo institucional.

Pero, ¿de veras pensamos que podremos acabar con el imaginario del crecimiento únicamente con cambios en nuestro lenguaje, nuestras cosmovisiones o nuestras formas de narrar (Prádanos, 2018)? Una lectura atenta de Castoriadis permite entender que no (Almazán Gómez, 2020).

Por un lado, porque el mundo material es la sede en la que reside todo imaginario. Pero, además, porque no es posible cambiar los imaginarios sin cambiar el mundo material. De ahí que sea peligroso aislar el concepto de hegemonía gramsciano de su teorización en torno a la revolución (Prádanos, 2018). De hacerlo, a lo sumo lo que obtendremos es un recetario para construir mayorías de opinión o mayorías electorales, más o menos aquello de lo que es capaz el neopopulismo a la Laclau (2016). Y no siempre, como demuestra Podemos. Lo que desde luego no lograremos es una transformación profunda de nuestros metabolismos (Toledo, 2013), condición indispensable de una respuesta que nos permita fracasar mejor (Riechmann, 2013) en tiempos del Antropoceno.

Otro elemento cuestionable del marco teórico del libro es la sobrevaloración de la importancia que tiene la definición de lo humano en la dominación moderna. Ésta lleva a Prádanos, como a muchos otros autores y autoras, a defender la necesidad de un "ambientalismo posthumano". Pero, como afirma Riechmann (en prensa), el imperativo de pensar más allá del antropocentrismo no puede significar desconocer la singularidad humana, comenzando por sus posibilidades destructivas.

$\mathrm{O}$, dicho de otro modo, sería un error tratar de superar el antropocentrismo negando la especificidad de lo humano. Es indudable que, en tanto que seres humanos, nuestra condición básica es la interdependencia y la ecodepencia (Riechmann, 2016). Que la existencia de una prerrogativa que nos daría derecho a disponer del resto de elementos de Gaia (de Castro Carranza, 2019) no es más que una locura producida por la pesadilla mecánica del mundo industrial, es evidente. Pero, ¿implica eso dejar de intentar comprender lo particular de lo humano y, más aún, abandonar el humanismo?

Como Riechmann (2014) ha señalado en muchas ocasiones, nuestras singularidades nos hacen animales con responsabilidades especiales. Responsabilidad ante la situación presente $\mathrm{y}$, sobre todo, ante su eventual solución. Pero, además, es importante entender que humanismo, o Ilustración, nunca fueron sinónimo exclusivo de eurocentrismo, imperialismo, androcentrismo, racismo, clasismo... Más bien al contrario, como nos recuerda Garcés (2017), la Ilustración deja la puerta abierta a la posibilidad de un humanismo autocrítico que sea descolonial, democrático, feminista, intercultural y, añadiríamos, gaiano.

Apostar por el humanismo frente a lo posthumano, además, salvaguardaría a un autor explícitamente crítico con el transhumanismo como Prádanos (2018) de las filias de autoras que como Braidotti aceptan la tecno- ciencia como un hecho consumado, la abrazan de manera triunfal y, aún más, tienen el mal gusto de continuar defendiendo hoy la existencia de una neutralidad normativa de la tecnología -Braidotti, 2015, p. 59, citado en Riechmann (en prensa)-. Error en el que, en cambio, Prádanos (2018) no incurre. Ya que, además, haría imposible su denuncia y desmontaje del mito del tecnooptimismo y del solucionismo tecnológico, uno de los principales obstáculos a la hora de construir imaginarios y metabolismos decrecentistas.

En la segunda parte de su libro, "Ecocriticismo urbano y estudios culturales españoles", Prádanos aboga por la construcción de estudios urbanos que introduzcan la dimensión metabólica en su ecuación. O, dicho de otro modo, que entiendan que más allá de las transformaciones que puedan hacer las ciudades más inclusivas o democráticas, nuestras ciudades (y sus imaginarios) tienen la necesidad imperiosa de cerrar la brecha metabólica por la que hoy se desangran.

Mediante el estudio de varios productos culturales, Prádanos ofrece una tipología interpretativa que permitiría clasificar diferentes representaciones culturales de la ciudad. Ésta, que salvo un punto específico considero bastante acertada y útil, distingue hasta cuatro categorías. Por un lado, aquellas expresiones culturales destinadas a hacer visible la crisis de la "máquina de crecimiento urbano" y su dependencia de los combustibles fósiles. En el desarrollo conceptual de esta tipología destaca la sintética pero brillante crítica de las smart cities desarrollada por el autor (Prádanos, 2018).

En segundo lugar, el libro aborda aquellas representaciones que retratan futuros post-petróleo que serían el resultado de un colapso del actual modelo urbano. Relatos que, en opinión del autor, no favorecen la creación de imaginarios alternativos al mostrar como prácticamente la única opción posible la creación de sociedades injustas, jerarquizadas y, pese a ello, aún atadas al pernicioso imaginario capitalista del crecimiento.

En tercer lugar, se encontrarían aquellas expresiones culturales que representan, en opinión del autor, la posibilidad de escapar (un término importante para la discusión posterior) de la máquina del crecimiento urbano mediante el asentamiento voluntario o forzoso en enclaves rurales. Es decir, aquellas que señalan que la única posibilidad que quedará en el actual y futuro contexto de escasez y crisis del modelo urbano será abandonar el espacio urbano, ya sea por considerarlo indeseable o por su propio colapso.

En cuarto y último lugar, y considerado por el autor como el tipo de expresiones culturales de la ciudad con mayor potencial para impulsar el tipo de transformaciones necesarias hoy para darle cuerpo a un imaginario poscrecimiento, se encontraría la categoría que engloba las representaciones de nuevos imaginarios urbanos poscrecimiento en los que la ciudad abandona su característico metabolismo lineal para abrazar un metabolismo circular que le haría merecer el apelativo de Ecopolis.

En esta segunda parte, la crítica necesaria es más de orden político que teórico. Llama la atención el modo en que en su descripción de la tercera categoría el autor se muestra implacablemente crítico con las propuestas 
que ponen el mundo rural en el centro. Simplificando su argumento, Prádanos (2018) entiende que posicionarse política y materialmente en el mundo rural no es más que una huida fútil, y quizá contraproducente. Primero, porque la naturaleza necesariamente local de estos proyectos impediría que pudieran hacer frente a las relaciones de poder del capitalismo global. Segundo, su capacidad política sería nula ya que, al encontrarse el metabolismo destructivo de nuestras sociedades especialmente encarnado en las ciudades, limitarse a darles la espalda no sería más que un proceso simbólico, estéril. Y, tercero aún, el tipo de sentido de pertenencia que este tipo de proyectos lleva implícito podría llegar a ser incluso contraproducente al ir en contra de un eco-cosmopolitismo, una ciudadanía global, en teoría necesaria para luchar contra la crisis actual.

He rebatido, o problematizado, muchos de esos puntos en otros lugares, por ejemplo (Almazán Gómez, 2019). De hecho, pienso que una postura como la de Prádanos únicamente es posible si se cierran los ojos ante las dificultades y peligros de una alternativa que se piense global. Además de ignorar las potencialidades políticas de una propuesta que ponga en el centro la construcción de autonomía material.

Pero quizá lo que más sorprende es que esta postura ultracrítica con el mundo rural se confronte con una defensa ultraoptimista, poco desarrollada y francamente acrítica del proyecto de construcción de un metabolismo social circular en las ciudades. Porque, ¿qué significaría un metabolismo circular en ciudades como las actuales megalópolis? ¿Es posible? ¿No sería algo parecido a hacer de nuestras ciudades un conglomerado de pequeños pueblos/barrios con un alto grado de autonomía material? ¿No es ilusorio pensar, como hace el autor (Prádanos, 2018), que los gobiernos municipales del cambio van a abrazar ese tipo de transformaciones radicales cuando a lo más que han llegado es a "renaturalizaciones" del espacio público que han seguido ahondando en la ruptura del lazo social neoliberal y la mercantilización de los espacios comunes? Además, incluso si fuera así, ¿no es injustificado pensar que únicamente los gobiernos municipales de las ciudades del mundo serían capaces de hacer frente a dinámicas, y poderes, globales y multinacionales? ¿No nos enfrentamos al mismo problema de escala?

En la última parte del libro, "Desechos, desastre, refugiados y la agencia no humana" el autor aplica el marco desarrollado en el resto del libro al estudio de diferentes cuestiones particulares. Por un lado, un inspirado e impecable análisis de la cuestión migratoria hoy en conexión con el neocolonialismo y la explotación de la naturaleza (Prádanos, 2018). Por otro, la propuesta de una política ecológica de los desechos que permita estudiar la importancia de los desechos, materiales y humanos, para hacer visible el funcionamiento disfuncional del capitalismo industrial hoy.

Y, por último, se incluye en el libro una crítica muy acertada de las creaciones culturales que pretenden realizar una pedagogía de la catástrofe. Estas representaciones catastrofistas, de las que estudia dos casos particulares, servirían más para reproducir los valores e imaginarios dominantes, llegando incluso a presentarlos como capaces de sobrevivir al colapso del orden de Gaia, que para poner en marcha un movimiento por el decrecimiento. Éste último requeriría más bien de una pedogogía decrecentista que relatara e imaginara sociedades justas, sostenibles y libres en escenarios pospetróleo y poco intensivos en consumo de materiales y energía.

Quizá la última crítica que se pueda realizar al desarrollo de esta parte, en conexión de nuevo con la asunción del marco hegemónico en los estudios culturales, sea el modo en que el autor insiste en renunciar al concepto de naturaleza en la línea de las viejas propuestas de Bruno Latour. Pero, ¿necesitamos deshacernos de la naturaleza o entenderla de otro modo? De nuevo aquí abandonar el antropocentrismo o los imaginarios que legitimaron nuestra explotación de la naturaleza (Merchant, 1989; Mumford, 2011) no pasa por imitar el movimiento de los ecomodernistas cuando rechazan la existencia de nada más allá de lo humano (Arias-Maldonado, 2015). Nuestra tarea hoy es entender que somos parte de Gaia, ecodependientes. Y que, por tanto, las acciones que puedan quebrar su complejo baile nos pondrán a nosotros y al resto de seres en un peligro mortal. Algo que el mismo Latour (2019) ha comprendido, renegando en parte de sus antiguas convicciones.

Por tanto, el programa para la construcción de un movimiento político no antropocéntrico y poscrecimiento/decrecentista no debería ser dejar ir a la naturaleza, la excepcionalidad humana y el crecimiento mediante el desmantelamiento de la máquina antropológica (Prádanos, 2018). Quizá esta transformación política imprescindible se parezca más bien a comprender que somos hijos de Gaia, animales singulares con responsabilidades especiales que tienen la obligación de acabar con el crecimiento mediante la transformación metabólica e imaginaria de nuestras sociedades capitalistas industriales. Una transformación que necesariamente implicará cambiar nuestros modos de vida, aumentar nuestra autonomía material, re-ruralizar nuestro metabolismo y asumir una subjetividad del límite.

\section{Referencias}

Agamben, G. (2011). ¿Qué es un dispositivo? (R. J. Fuentes Rionda, Trad.). Sociológica. Revista del departamento de sociología, 26(73), 249-264.

Almazán Gómez, A. (2019). Atrincherados en los surcos. La nueva ruralidad como propuesta necesaria y deseable. Cultura, ciudadanía, pensamiento 7. Recuperado de: https://culturayciudadania.culturaydeporte.gob.es/dam/jcr:00f203cd-34a7-45d5be1d-b32176ba0235/adrian-almazan.pdf

Almazán Gómez, A. (2020). La ontología del mundo socio-histórico de Cornelius Castoriadis. El problema de la sede de las significaciones imaginarias sociales. Las Torres de Lucca. Revista Internacional de Filosofía Política, 9(16), $203-229$. 
Arias-Maldonado, M. (2015). Recuperado de: Environment and society: Socionatural relations in the Anthropocene. Springer. Recuperado de: http://site.ebrary.com/id/11031063

Braidotti, R. (2015). Lo posthumano. Barcelona: Gedisa.

Castoriadis, C. (1983). La Institución imaginaria de la sociedad. Vol 1. Marxismo y teoría revolucionaria (A. Vicens, Trad.; Vol. 1). Barcelona: Tusquets.

Castoriadis, C. (1989). La Institución imaginaria de la sociedad. Vol 2. El imaginario social y la institución (M.-A. Galmarini, Trad.; Vol. 2). Barcelona: Tusquets.

Cusset, F. (2005). French theory. Foucault, Derrida, Deleuze \& Cia. Y las mutaciones de la vida intelectual en Estados Unidos. Santa Cruz de Tenerife: Editorial Melusina.

de Castro Carranza, C. (2019). Reencontrando a Gaia. A hombros de James Lovelock y Lynn Margulis. Málaga: Ediciones del Genal.

Garcés, M. (2017). Nueva ilustración radical (Primera). Barcelona: Anagrama.

Laclau, E. (2016). La razón populista (S. Laclau, Trad.). México: Fondo de Cultura Económica.

Latour, B. (2019). Dónde aterrizar: cómo orientarse en politica (P. Cuartas, Trad.). Barcelona: Taurus.

Laval, C., \& Dardot, P. (2013). La nueva razón del mundo: Ensayo sobre la sociedad neoliberal. Barcelona: Gedisa.

Lyotard, J.-F. (1989). La condición postmoderna: Informe sobre el saber (M. Antolín Rato, Trad.; 4. ed). Madrid: Cátedra.

Merchant, C. (1989). The death of nature: Women, ecology, and the scientific revolution. Nueva York: Harper \& Row.

Mumford, L. (2011). El pentágono del poder: El mito de la máquina (dos) (J. Rodríguez Hidalgo, Trad.). Logroño: Pepitas de Calabaza Ed.

Riechmann, J. (en prensa). Informe a la subcomisión del Cuaternario. Madrid: Árdora.

Riechmann, J. (2013). Fracasar mejor: Fragmentos, interrogantes, notas, protopoemas y reflexiones. Zaragoza: Olifante.

Riechmann, J. (2014). Acerca de la condición humana. En A. Diéguez \& J. M. Atencia Páez (Eds.), Naturaleza animal y humana (pp. 229-266). Madrid: Biblioteca Nueva.

Riechmann, J. (2016). Ética extramuros (segunda edición revisada y ampliada de Interdependientes y ecodependientes). Madrid: Ediciones UAM.

Steffen, W., Broadgate, W., Deutsch, L., Gaffney, O., and Ludwig, C. (2015). The trajectory of the Anthropocene: The Great Acceleration. The Anthropocene Review, 2(1), 81-98. https://doi.org/10.1177/2053019614564785

Toledo, V. M. (2013). El metabolismo social: Una nueva teoría socioecológica. Relaciones. Estudios de historia y sociedad, 34(136), 41-71.

Adrián Almazán Gómez

Universidad de Deusto

E-mail: adrian.almazan@deusto.es https://orcid.org/0000-0003-0373-0642 